原著

\title{
くも膜下出血の予後は改善したか？
}

一長期間長崎県悉皆調査データの解析結果からー

\author{
上之郷眞木雄 ${ }^{1}$, 鳥羽保 ${ }^{1}$, 牛島隆二郎 ${ }^{1}$ \\ 林之茂 ${ }^{1}$, 米倉 正大 ${ }^{2}$, 永田 泉 ${ }^{3}$
}

\section{Changes in Outcome of Subarachnoid Hemorrhage: Analysis of the NAGASAKI SAH Data Bank, 1993-2009}

\author{
Makio Kaminogo, M.D., ${ }^{1}$ Tamotsu ToBa, M.D., ${ }^{1}$ Ryujiro UshiJima, M.D., ${ }^{1}$ \\ Yukishige Hayashi, M.D., ${ }^{1}$ Masahiro YonekuRA, M.D., ${ }^{2}$ and Izumi NaGATA, M.D. ${ }^{3}$ \\ ${ }^{1}$ Department of Neurosurgery, Sasebo City General Hospital, Sasebo, Nagasaki, ${ }^{2}$ Department of \\ Neurosurgery, Nagasaki Medical Center, Omura, Nagasaki, and ${ }^{3}$ Department of Neurosurgery, \\ Nagasaki University School of Medicine, Nagasaki, Japan
}

\begin{abstract}
Summary: In this population-based study, we evaluated the changes of case-fatality rates and full-recovery rates in subarachnoid hemorrhage at three months and determined trends in these rates during the period of 1993-2009. We retrospectively reviewed 4,308 patients registered in the Nagasaki SAH Data Bank from 1993 to 2009. All neurosurgical units in Nagasaki Prefecture participate in Nagasaki SAH Data Bank. From 1993 to 2000, case fatality rates were 25.5\%, 29.8\%, $37.1 \%$, and $51.2 \%$ in patients at ages $40-59,60-69,70-79$, and $\geq 80$ years, respectively. Whereas, from 2001 to 2009 , these rates improved to $20.0 \%, 20.0 \%, 27.4 \%$, and $39.2 \%$, respectively. There were significant differences in all age groups. On the other hand, there were no significant changes in full-recovery rates between 1993-2000 and 2001-2009. The proportions of high grade SAH (Hunt \& Hess Grade IV and V) and low grade SAH (Hunt \& Hess Grade I and II) did not differ significantly in all age groups between 1993-2000 and 2001-2009. In all age groups, rates of radical treatment, especially with coil embolization, for ruptured aneurysms increased significantly in 2001-2009.

Advances in radical treatment and intensive management might reduce mortality in SAH but might not result in improvement of full-recovery rates at three months. Long term follow-up studies are required to accurately evaluated the favorable outcome of severe SAH.
\end{abstract}

\section{Key words: \\ - subarachnoid hemorrhage \\ - prognosis \\ - population based study \\ - case-fatality rate}

Surg Cereb Stroke

(Jpn) 40: 229-232, 2012

\section{はじめに \\ くも膜下出血の年間発症症例数には地域差が存在するも \\ のの人口 10 万人当たり 10-30人前後で1)3)5), その頻度は 全脳卒中の約 $10 \%$ 前後 $\left.{ }^{6)} 8\right)$ とけっして高くはない. しかし 死亡率は $30 \%$ を超えると報告 ${ }^{7)}$ () され予後は他の脳卒中に}

\footnotetext{
${ }^{1}$ 佐世保市立総合病院 脳神経外科, ${ }^{2}$ 国立病院機構 長崎医療センター 脳神経外科, ${ }^{3}$ 長崎大学医学部 脳神経外科(受稿日 2012. 1.10) (脱稿日 2012.2.15) 〔連絡先： $7857-8511$ 長崎県佐世保市平瀬町 9-3 佐世保市立総合病院 脳神経外科 上之郷眞木雄] [Address correspondence: Makio Kaminogo, M.D., Department of Neurosurgery, Sasebo City General Hospital, 9-3 Hirase-machi, Sasebo, Nagasaki 857-8511, Japan]
} 


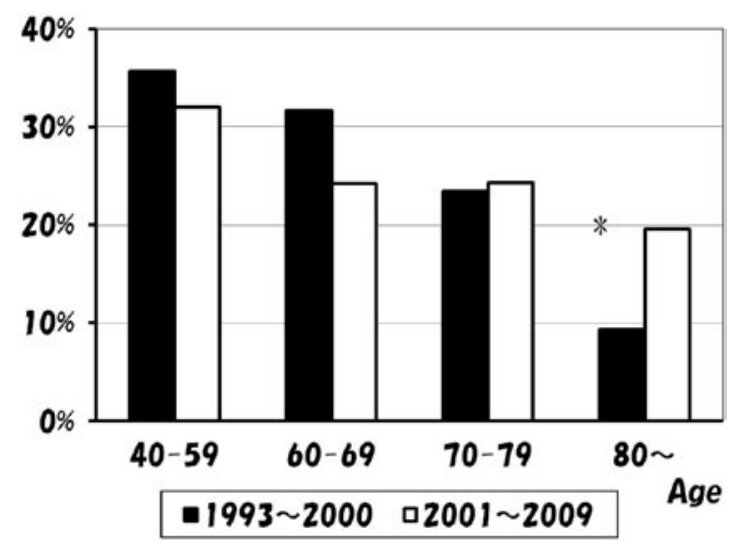

Fig. 1 Age related distribution of patients with subarachnoid hemorrhage in 1993-2000 (black column) and 2001-2009 (white column). Rate of aged patients ( $\geq 80$ year-old) was significantly higher in 2001-2009 (*: $\mathrm{P}<0.05)$.

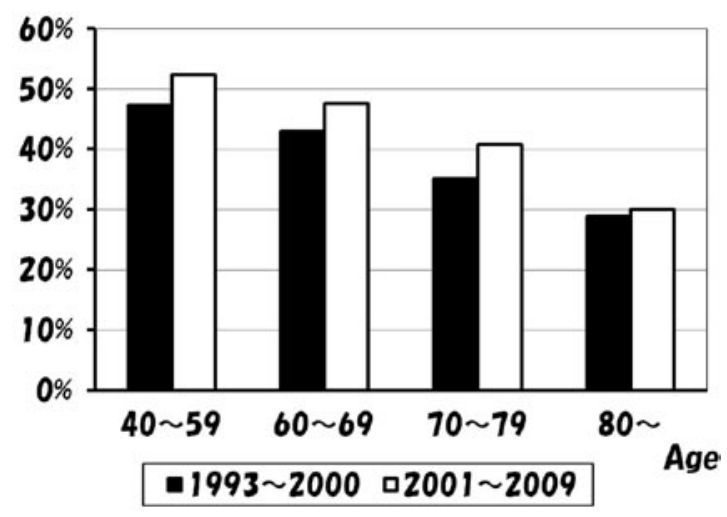

Fig. 2 Rates of good clinical grade (Hunt \& Hess I, II) in each age group, 1993-2000 (black column) and 2001-2009 (white column). There was no significant difference in each age group.

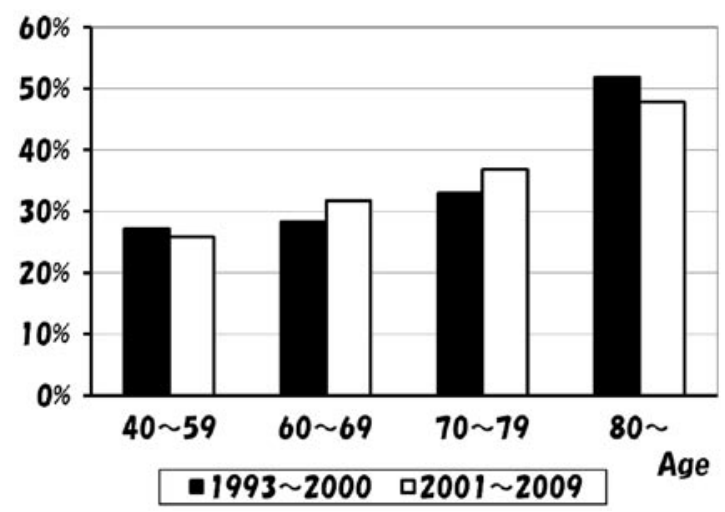

Fig. 3 Rates of poor clinical grade (Hunt \& Hess IV, V) in each age group, 1993-2000 (black column) and 2001-2009 (white column). There was no significant difference in each age group.

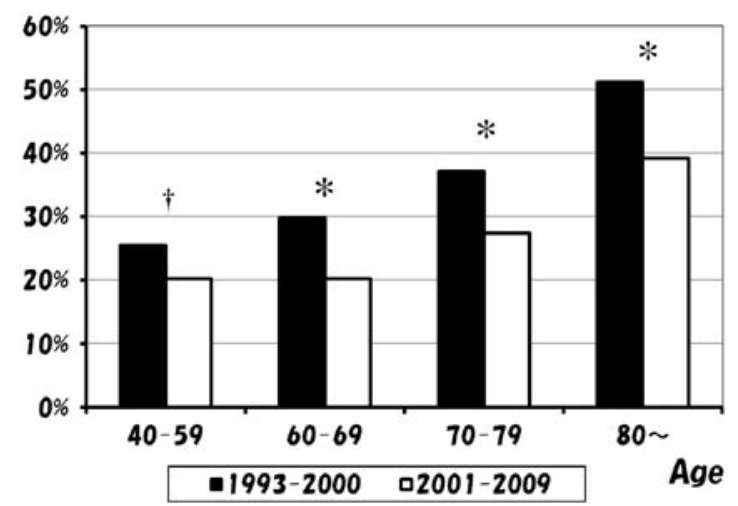

Fig. 4 Age specific case fatality rates in 1993-2000 (black column) and 2001-2009 (white column). There was significant improvement in all age categories. (t: $P=0.0104 *$ : $P<0.001)$

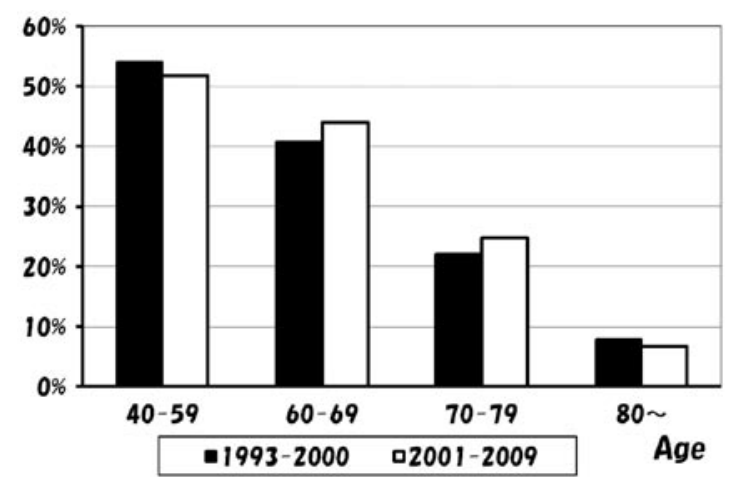

Fig. 5 Age specific incidence of good clinical outcome in 1993-2000 (black column, Glasgow Outcome Scale; GR) and 2001-2009 (white column, modified Rankin Scale; 0,1). There was no significant improvement.

比しても不良であり, その改善は脳卒中治療の重要な課題 の 1 つである. 近年の脳動脈瘤に対する治療手段の発達と 治療技術の向上，さらにはくも膜下出血症例に対する管理 法の充実によって，その予後が改善したか否か長崎県全脳 神経外科施設が登録するデータベースを基に検討した。

\section{対象と方法}

1993 年 1 月から 2009 年 12 月までの 17 年間に長崎県内 の全脳神経外科施設のいずれかに入院したくも膜下出血症 例のうち, 長崎県内に在住する 40 歳以上の全症例を対象 とした．これら症例を 1993 年 1 月から 2000 年 12 月まで の 8 年間を前期, 2001 年 1 月から 2009 年 12 月までの 9 年間を後期に分けて男女別, 年齢別に発症 3 力月後の死亡 率と予後良好例比率について比較検討した。な予後評価 法については前期は Glasgow Outcome Scale (GOS)を用 いていたが, 後期からは modified Rankin Scale (mRS)に 
Table 1 Rate of radical treatment

\begin{tabular}{|c|c|c|c|c|c|c|}
\hline & \multicolumn{3}{|c|}{ Former group (1993-2000) } & \multicolumn{3}{|c|}{ Latter group (2001-2009) } \\
\hline & Craniotomy & $\begin{array}{c}\text { Endovascular } \\
\text { surgery }\end{array}$ & $\begin{array}{c}\text { Total treated } \\
\text { cases }\end{array}$ & Craniotomy & $\begin{array}{c}\text { Endovascular } \\
\text { surgery }\end{array}$ & $\begin{array}{c}\text { Total treated } \\
\text { cases }\end{array}$ \\
\hline \multicolumn{7}{|l|}{ age } \\
\hline $40-59$ & $\begin{array}{c}514 \\
(75.0 \%)\end{array}$ & $\begin{array}{c}5 \\
(0.7 \%)\end{array}$ & $\begin{array}{c}519 \\
(75.8 \%)\end{array}$ & $\begin{array}{c}617 \\
(73.6 \%)\end{array}$ & $\begin{array}{c}82 \\
(9.8 \%)\end{array}$ & $\begin{array}{c}699 \\
(83.4 \%)^{*}\end{array}$ \\
\hline $60-69$ & $\begin{array}{c}465 \\
(76.5 \%)\end{array}$ & $\begin{array}{c}4 \\
(0.7 \%)\end{array}$ & $\begin{array}{c}469 \\
(77.1 \%)\end{array}$ & $\begin{array}{c}404 \\
(71.6 \%)\end{array}$ & $\begin{array}{c}60 \\
(10.6 \%)\end{array}$ & $\begin{array}{c}564 \\
(82.3 \%) \dagger\end{array}$ \\
\hline $70-79$ & $\begin{array}{c}303 \\
(67.3 \%)\end{array}$ & $\begin{array}{c}5 \\
(1.1 \%)\end{array}$ & $\begin{array}{c}308 \\
(68.4 \%)\end{array}$ & $\begin{array}{c}395 \\
(68.5 \%)\end{array}$ & $\begin{array}{c}55 \\
(9.5 \%)\end{array}$ & $\begin{array}{c}577 \\
(78.0 \%)^{*}\end{array}$ \\
\hline$\geq 80$ & $\begin{array}{c}65 \\
(38.2 \%)\end{array}$ & $\begin{array}{c}1 \\
(0.6 \%)\end{array}$ & $\begin{array}{c}66 \\
(38.8 \%)\end{array}$ & $\begin{array}{c}196 \\
(47.1 \%) \dagger\end{array}$ & $\begin{array}{c}51 \\
(12.3 \%)\end{array}$ & $\begin{array}{c}247 \\
(59.4 \%)^{*}\end{array}$ \\
\hline
\end{tabular}

変更した，そのため発症 3 カ月後の予後を直接には比較で きないが, GOSの good recovery (GR) と modified Rankin Scale 0,1 をほぼ発症前の状態に回復した社会復帰群とし てその頻度を比較検討した. 入院時のくも膜下出血重症度 はHunt \& Hess grade を用いて評価し, grade I, II を軽 症, grade IV, Vを重症とした。

統計学的検討はカイ 2 乗検定を用い, 危険率 $5 \%$ 未満を もって統計学的に有意差ありとした.

\section{結果}

40 歳以上の対象症例は前期 8 年間 1,913 例, 後期 9 年間 2,395 例であり, 後期において高齢者とくに 80 歳以上の症 例割合が 9.3\% から $17.4 \%$ へ有意に増加を示していた (Fig. 1, $\mathrm{P}<0.001)$. 年齢群別に入院時のくも膜下出血軽症例お よび重症例の割合とその推移を比較したところ, 軽症例の 比率は年齢とともに低下し逆に重症例の比率は年齢ととも に増加していた，しかしいずれの年齢群においても，軽症 例および重症例の比率に関しては前期と後期の間に有意な 変化を認めなかった(Fig. 2, 3).

死亡率は前期, 後期とも年齢とともに増加を示し, 予後 良好群の頻度は年齢とともに低下を示した (Fig. 4, 5)。40 歳以上のくも膜下出血症例における全体の死亡率は前期 $31.9 \%$ から後期 $22.9 \%$ 一低下傾向を示し，年齢別にみても すべての群で前期に比し後期で有意な低下が示された (Fig. 4). 一方予後良好である社会復帰例の全体での頻度は前 期 38.2\% に対して後期 35.6\% と改善を認めず，いずれの年 齢群においても前期と後期の間に有意な変化を認めなかっ た(Fig. 5).

動脈瘤根治術が行われた頻度をみると, 全症例に対する 開頭術が行われた頻度は 80 歳以上の群でのみ前期に比べ 後期で有意に増加しており，40-59 歳代，60 歳代では逆に
ややその頻度は低下していた。 しかし血管内治療症例数の 頻度は前期に比べて後期ではいずれの年齢群でも $10 \%$ 前 後増加して抢り，その結果開頭術と血管内治療を合わせた 根治術症例の頻度はすべての年代で後期に有意な増加を認 めた (Table 1).

\section{考察}

1973 年から 2002 年までのデータを用いた Nieuwkamp ${ }^{9}$ らのメ夕解析や 1980 年から 2005 年までのデー夕を用いた Lovelock ${ }^{7}$ らのメ夕解析によって, くも膜下出血の死亡率 が年間 0.6-0.9\% 低下していることが示されている. しか しこれらの検討では日本と比べ死亡率が約 10\% 高い欧州 やオーストラリア，ニュージーランドなどのデータが用い られており，わが国に直接当てはまるか否か明らかではな い. また機能予後は死亡率とともにくも膜下出血における 重要な検討項目ではあるが, population-based 研究におい て社会生活復帰率など予後良好例の頻度が改善しているか 否かを検討している報告はそしい.

わが国の解析結果については, 出雲市における 1980-1989 年と 1990-1998 年の死亡率を比較した検討にお いて，80 歳未満の症例に扔ける死亡率は $38 \%$ から $26 \%$ 一 有意に低下したものの, 80 歳以上の症例では死亡率が 63\% から $79 \%$ と改善がなく, 高齢者症例の増加のため全 体の死亡率は 39\% から 36\% へとわずかの改善しか認めな かったと報告 ${ }^{4)}$ されている. 一方で八代市の 1989 年から 2008 年までの解析結果では, 50 歳代の死亡率がやや増加 し 80 歳代の死亡率には変化はなかったとしており, 逆に 人口の高齢化に伴い全体として予後不良症例が増加してい $た^{13)}$. 今回の検討でも 80 歳以上の高齢者が占める割合は 9.3\% から $17.4 \%$ へ有意に上昇がみられ, 高齢者症例の増 加が示された．しかし死亡率については過去の報告と異な 
り 80 歳以上の症例を含めてすべての年代で有意に改善し， とくに 60 歳以上のグループでは $10 \%$ 前後の低下が示され, その結果として全体の死亡率は $31.9 \%$ から $22.9 \%$ に低下を 認めた。 しかし社会復帰率はいずれの年代においても改善 が認められず, 死亡率は低下したものの発症 3 カ月の時点 での社会復帰率は改善しなかったとの結果であった。

くも膜下出血の重症度と年齢は最も重要な予後因子であ るが11), 重症度についてはすべての年齢群で前期と後期の 間に有意差を認めなかった，根治治療と予後との関連につ いては, 開頭術の入院全症例に対する頻度は 80 歳以上で 有意な増加を認めたものの 79 歳以下では各年代とも変化 を認めなかった。しかし 2000 年を境として血管内治療が 急速に広がり, 開頭術と血管内手術を合わせた根治治療症 例の頻度はいずれの年代でも後期で有意な増加を示した. このように 2001 年以降みられる血管内治療症例の増加, さらに 80 歳以上の高齢者に対する積極的な開頭手術適応 の拡大は，これまでの本邦における検討症例群とは異なっ た背景であり, その結果死亡率が低下した可能性が強く推 測される. しかし根治治療率の上昇が発症 3 力月の時点に おける社会復帰率の改善に繋がる結果は得られなかった. 積極的な治療によって死亡例は減少したが高度障害例が逆 に増加し，この傾向はとくに高齢者に多いとの指摘もあ $る^{13)}$. 本研究は後乃向き検討のため予後評価スケールが前 期と後期で異なってしまい, その結果残存する機能障害の 程度に関して正確な比較ができなかった，今後 modified Rankin Scaleに統一しての症例蓄積が必要と考える.さ らに重症くも膜下出血症例においては症状回復に時間を要 し, 機能予後の判定には 3 カ月は短すぎることは日常の診 療でも少なからず経験する，実際に重症例に対して積極的 な治療を行うことで, 6 力月さらには 1 年と長期の経過後 にはかなりの割合で良好な機能予後が得られるとの報告も ある ${ }^{21012)}$. 今回の検討では社会復帰率について 6 力月後 さらには 1 年後の長期予後を検討できておらず，そのため 真の社会復帰率を評価できなかった可能性も十分にあり， この点でもさらなる検討が必要と考えられた。

\section{まと め}

1. 長崎県内のいずれかの脳神経外科施設に入院した, 長 崎県内に在住する 40 歳以上のくも膜下出血症例を対象 に，前期 (1993-2000 年)に比べ後期 (2001-2009 年)にお いてくも膜下出血の予後が改善したか否かを検討した.

2. 40-59 歳, 60-69 歳, 70-79歳, 80 歳以上のすべての年 代で死亡率は有意に低下した。

3. 発症 3 カ月後の社会復帰比率については, すべての年
代で有意な変化を認めなかった.

4. 後期群において血管内手術症例の増加に伴い脳動脈瘤 根治治療の頻度が有意に上昇しており，死亡率の低下 について根治術症例頻度の増加が関与している可能性 が示唆された。一方で予後良好群の頻度推移について は，長期的な予後評価が必要と考えられた。

\section{文献}

1) de Rooij NK, Linn FH, van der Plas JA, et al: Incidence of subarachnoid haemorrhage. a systemic review with emphasis on region, age, gender and time trends. $J$ Neurol Neurosurg Psychiatry 78: 1365-1372, 2007

2) Gupta SK, Ghanta RK, Chhabra R, et al: Poor-grade subarachnoid hemorrhage. Is surgical clipping worthwhile? Neurol India 59: 212-217, 2011

3) Hamada J, Morioka M, Yano S, et al: Incidence and early prognosis of aneurysmal subarachnoid hemorrhage in Kumamoto prefecture, Japan. Neurosurgery 54: 31-38, 2004

4) Inagawa $\mathrm{T}$ : Trends in incidence and case fatality rates of aneurysmal subarachnoid hemorrhage in Izumo City, Japan, beteen 1980-1989 and 1990-1998. Stroke 32: 14991507, 2001

5) Kozák N, Hayashi M: Trends in the incidence of subarachnoid hemorrhage in Akita Prefecture, Japan. $J$ Neurosurg 106: 234-238, 2007

6) Kubo M, Kiyohara Y, Kato I, et al: Trends in the incidence, mortality and survival rate of cardiovascular disease in Japanese community: the Hisayama Study. Stroke 34: 2349-2354, 2003

7) Lovelock CE, Rinkel GJE, Rothwell PM: Time trends in outcome of subarachnoid hemorrhage. Population-based study and systemic review. Neurology 74: 1494-1501, 2010

8) Morikawa U, Nakagawa H, Naruse $Y$, et al: Trends in stroke incidence and acute case fatality in a Japanese rural area, the Oyabe study. Stroke 31: 1583-1587, 2000

9) Nieuwkamp DJ, Setz LE, Algra A, et al: Changes in case fatality of aneurysmal subarachnoid hemorrhage over time, according to age, sex, and region: a meta analysis. Lancet Neurol 8: 635-642, 2009

10) Pereira AR, Sanchez-Pefia P, Biondi A, et al: Predictors of 1-year outcome after coiling for poor-grade subarachnoid aneurysmal hemorrhage. Neurocrit Care 7: 18-26, 2007

11) Rosengart AJ, Schultheiss KE, Tolentino J, et al: Prognostic factors for outcome in patients with aneurysmal subarachnoid hemorrhage. Stroke 38: 2315-2321, 2007

12) Taylor CJ, Robertson F, Brealey D, et al: Outcome in poor grade subarachnoid hemorrhage patients treated with acute endovascular coiling of aneurysms and aggressive intensive care. Neurocrit Care 14: 341-347, 2011

13）山城重雄, 吉田顯正, 等 泰幸, ほか：地方都市における くも膜下出血の治療成績の変化，単独施設における 20 年間 587 例の解析結果から. 脳卒中の外科 39: 406-413, 2011 